\title{
Understanding Social Exclusion from Environmental (In) justice Perspective: An Emphasis on India's North East
}

\author{
Jhimli Bhattacharjee \\ Department of Sociology, Assam University, Silchar, India
}

\begin{abstract}
The lack of equal access of people to safe and desired environment can add another dimension to the concept of social exclusion. The incorporation of the dimension of environmental justice can thus broaden the horizon of the concept of social exclusion. The paper thus attempts to understand social exclusion from environmental justice perspective and tried to understand the social exclusion of tribal people in North East India caused equally by the lack of safe and desired environment.
\end{abstract}

Keywords: Social exclusion, environmental justice, North East India, inclusion, growth

\section{Introduction}

The paper tries to understand social exclusion from environmental justice perspective. While social exclusion emerged as an approach to address all kinds of deprivations and sufferings, the environmental justice approach helps to complement the understanding of social exclusion by emphasizing on new kinds of sufferings and problems faced by the different categories of people because of unequal access to safe and desired environment. Mostly this kind of exclusion emerged out of a growth oriented development paradigm with its continuous aggression to the life and livelihood of certain segments of people who bear all costs of such development initiative in terms of unsafe environment, exposure to unhealthy life and insecure livelihood. The paper thus tries to juxtapose two alien concepts to understand the condition of the third world country like India with a special attention to the experience of its 'North East'.

\section{Environmental Justice Approach}

Environmental justice approach emerged out of a criticism of the mainstream environmentalism which has focused on wilderness preservation, pollution abatement and population control. It entails the fulfillment of basic needs through the equitable distribution and use of natural and social resources and freedom from the effects of environmental misuse, scarcity and pollution. According to philosopher Peter Wenz, environmental justice is concerned with the problem of distributive justice. It has been seen that the economic growth and development oriented projects generally benefit a small section of people while the rest are not only deprived of it but also often adversely affected. Environmental justice thus focuses on the need for environmental laws and policies that must embody principles of environmental justice that a majority of the people agrees as reasonable. Collin et.al (1995) in their study on Environmental Racism maintained that the people of color are suffering from the unhygienic effect of toxic waste and garbage. In their view this arises because of schism in planning between housing and community development and environmental planning.

Robert Bullard similarly maintained that in the United States of America environmental regulations have not uniformly benefited all segments of society. People of color are disproportionately harmed by industrial toxins on their jobs and in their neighborhoods. For Bullard racism plays a key factor in environmental planning and decision making. To him environmental racism is reinforced by government, legal, economic, political and military institutions, racism provides whites of all class levels with an edge in gaining access to a healthy physical environment. In his words:

Whether by conscious design or institutional neglect, communities of color in urban ghettos, in "rural poverty pockets", or on economically impoverished Native American reservations face some of the worst environmental devastation in the nation. Clearly, racial discrimination was not legislated out of existence in the 1960s. While some significant progress was made during this decade, people of color continue to struggle for equal treatment in many areas, including environmental justice. Agencies at all levels of government, including the fundamental EPA, have done a poor job protecting people of color, from the ravages of population and industrial encroachment. It has thus been an uphill battle convincing wide judges, juries, government officials and policy makers that racism exists in environmental protection, enforcement, and policy formulation.

Thus it is maintained that environmental justice cannot simply be solved without social justice. Winova Laduke maintained that the most affected groups among the North American groups are native Americans, who lived to an ethical accountability to natural law. They relied on the animate world for sustenance, in compliance with natural law. The reciprocity between native Americans and nature created sustainable communities that 
contrast with the capitalist industrial model of accumulation. While raising the issue of devastating impact of energy development in these communities, Laduke shows how uranium and coal mining companies employed Indians on their own lands, but left them sick with lung and skin cancer. The shift from the nuclear to hydropower affected many northern American and Canadian tribes. In the late 1970s four of the ten largest coal strip mines in the country were on Indian lands and 100 percent of all federally controlled uranium production comes from Indian Reserves.

Shery Cable and Michael Benson maintained that the emergence of community based Grassroot organizations are the new trend of development which challenged the distributions of the costs of local environmental pollution and demand better protection of their lives and properties .

\section{Understanding social exclusion from environment justice perspective}

Social exclusion is an umbrella term which emphasizes on any form of exclusion of members from society. The term here has enough scope to understand exclusion from environmental justice perspective. The environmental justice perspective shows that the people of color have unequal share to toxic exposure, which also speaks of exclusion in terms of ethnic group who received unequal treatment from Government of United States. That environmental injustice as one kind of social exclusion can be derived from Silver's following list of the 'few things from which people must be excluded':

A livelihood ; secure, permanent employment; earnings; property credit or land; housing; minimal or prevailing consumption levels; education, skills and cultural capital; the welfare state; citizenship and legal equality; democratic participation; public goods; the nation and the dominant race; family and sociability; humanity, respect, fulfillment and understanding.

Thus an analysis of all things listed above shows that people of color are deprived of a good number of 'things' enlisted by Silver. The analysis of the cases of communities of color and their environmental injustices does not incorporate all kinds of injustices which is the result of the persistent inattention or recognition of the problem of all citizens equally. Thus the approach can have better scope to understand the extent of social exclusion when it will be applied to understand the situation of injustices practiced in other countries. While the social exclusion has its origin in European countries and environmental justice approach has its origin in the USA, both can complement each other to understand the sufferings of the people in India who are not only marginalized economically or politically but also in terms of safe environment and secure livelihood. The approach thus can incorporate not only the problems of the races or people of color in united states, but can also incorporate the particular segments of people caste or class or any kind of ethnic group who are persistently deprived by the dominant group in the society. Thus the approach has a scope to cover the "environmentalism of the poor', the dominant paradigm to understand the deprivations of the southern countries. Though there is a marked difference in both the approaches in terms of their origin and explanation as laid by some scholars as Williams and Mawdsley, an ample scope of similarity in these approaches is also observed in their adeptability to understand the vulnerability of the some sections of people which is rooted in the kind of social exclusion . While the people of color excluded from the dominant white race which is reflected in their exposure to toxins, the poor in southern countries have a vulnerability in terms of social and economic deprivations which is entailed in 'environmentalism of poor' and there after can be brought under the ambit of environmental justice approach. Hence understanding of social exclusion can be supported by Amartya Sen's proposal of understanding social exclusion as a cause and consequence of poverty. This exercise of Sen helps us to understand the dimension of the problem of social exclusion and environmental injustices that are rooted in poverty.

\section{Environmental injustice in India}

That the underprivileged always bear the brunt of environmental injustices can best be seen from the institutional arrangement the traditional Indian society had made for its people. The institution of untouchability, not only talks about social and religious injustices, but also about environmental injustices experienced by the outcastes. The outcastes are excluded from the Varna model because of no other cause than the cause of associating with occupation which involved pollution circumscribed by religious sanction (negative). This kind of environmental injustices takes myriad shape because of the religious sanction of purity and pollution which is considered as the essence of caste system by a good number of sociologists.

While British advent has created ground for abolition of untouchability de juri, it has introduced a new source of social exclusion by bringing India under the world system of capitalism. The over emphasis on economic growth by the post colonial Indian state along with the industrialization and its major requirement to increase power generation has led to the emergence of a number of development projects which in one side led to industrial pollution, on other side has led to huge displacement. According to Fernandes, between 1947-2000 such projects have caused some 50 to 60 million DP/PAP. It is also seen that most of the DP/PAP are assetless rural poor classes. The situation starts worsening with the structural adjustment programme with the three 
processes of liberalization, privatization and globalization. This can be assessed from the government's emphasis on SEZs for faster industrial development. It needs about 50,000 hectares of agricultural land for SEZs and 1.49 lakh hectares for all projects which include also industrial, mining, irrigation and infrastructural projects. Farmers are resisting for such kind of land diversion and acquisition because it leads to their miseries, deprivation, joblessness, rehabilitation problem and resettlement. It has been maintained that SEZ model of industrialization reduces jobs other than increases lead to another form of environmental injustices. While the Giant projects displace people from their natural habitat and livelihood, the industrial production units leads to other kind of environmental hazards where most of the sufferers are the poor and lower stratum of the society. There is ample evidence to the fact that despite the Environmental Protection Act a good number of workers suffer from unhealthy and unsafe occupation. This is the other dimension of the injustices mostly found both in urban as well as rural India, which though do not directly come under the ambit of environmentalism of the poor, but this is the other side of the story of growth economy that can be understood by bringing under the purview of environmental justice approach. There are repeated reports of occupational diseases from different industries. Dust born diseases are mainly found among the miners as in elsewhere. Cases of Silicosis, coal workers' Pneumoconiosis, manganese poisoning have been reported from Indian mines. Other occupational diseases such as noise induced hearing impairment, etc. have also been reported. Although, many surveys and studies have been conducted, comprehensive data on prevalence of occupational diseases in Indian mines are not available. This is primarily due to lack of proper occupational health surveillance procedures and comprehensive occupational diseases surveillance programme. While traditional occupational diseases continue to be prevalent, introduction of newer technologies and heavy machinery have enhanced or introduced new health hazards such as Noise, Vibration, Diesel Fumes, etc. It is estimated that unsafe work conditions is one of the leading cause of death and disability among India's working population. This can be estimated from the ILO (2) account that says around 403,000 people in India die every year due to work related problems. This shows 1000 workers die every day due to work related diseases.

\section{North East Experiences}

The environmental injustice in North East India began with the penetration of British to the land and resources of the region. Mostly inhabited by the 'ecosystem people', the region had vast patches of forest land full of biodiversity which was the basis of life and culture of the people. Along with the annexation of huge swathes of forests at national level to generate revenue by limiting essential access for many communities to timber and non timber forest products vast patches of forest land was brought under the control of British. The protest to such kind of injustices can be seen in the strong opposition of the local inhabitants against such acts of British. The Garo agitation under the leadership of Sonaram Sangma can be considered as one of the first protests to such acts. About one lakh Garos from the Garo Hills and adjoining Goalpara district came together to counter the series of legislations and conversion of their jungles and jhum lands into reserved forests. Under the leadership of Sonaram Sangma, the Garos demanded that Government put a stop to the policy of forest reservation in their territory. Nongbri states that "though the arrival of the British released the Garos from the clutches of Zamindars, reservation of forests not only impinged upon their rights and deprived them of their traditional sources of livelihood but also placed them under a new system of domination" . The Garos challenged the way the British took away their traditional rights over forest resources and demanded for the restoration of their rights to compensate them for the loss incurred there of. Forced to respond to the situation, the government appointed Mr.Arbuthnott, the Commissioner of Surma valley and hill districts, to look into the problem. The investigation upheld the Garo's charge. However while accepting the report of the inquiry the Government of India agreed not to proceed with further reservation but refused to accept the demand to return the disputed land to them ( Sinha, A.C.: 1993). This kind of act of British to appropriate the land and resources of tribal people not only deprives from their livelihood but also from their desired environment. While the British North East could experience the environmental injustices that are caused by the conservationist concern (rather utilitarian) as well as to supply raw materials to the core in England, the experience of North East in post colonial period is more alarming in so far as the right to land and forest is concerned. According to the information cited by Monirul Hussain, Assam accounts 21,330 displaced people (DPs) and 91,536 Project Affected People, together constituting 1,12,866 people, due to a selected number of environment protection related projects for seven districts of Assam This kind of displacement in one side talks of the injustices to the people in their right to inhabitation to the land, but also to their livelihood. The injustices can be further understood if a study of the extent of land acquisition is made. The total land acquired for national parks and wildlife sanctuaries of Assam occupy huge 7, 51,055.37 acres of land which according to Hussain, has been the highest among all kinds of categories of development projects.

The North east India has a direct bearing not only of the 'environmentalism of poor' approach to understand the experience of exclusion but it has a direct bearing of environmental justice approach. The region has been the victim of persistent neglect of the mainland India due to its geographically disadvantaged position 
which has a direct relation to the ethnic character of the people of the region who could not exert enough bargaining power to voice for their suffering. This is only the natural resource reserve and the Look East Policy which could draw attention to the region both geared by a drive for new market and business relation with neighboring south east countries the region is given some preference in the mainstream or mainland India. Besides its emphasis to protect forest which is rather an utilitarian drive to keep resource reserve without any concern for the ecosystem people of the region, the region has received huge grant from Government of India that is pouring funds for power generation projects. North East is regarded to have the potential to be India's largest Power House. The preliminary ranking study on the nation wide potential of hydroelectric schemes in October 2001 conducted by the Central Electricity Authority (CEA), gives Brahmaputra the highest potentiality mark. The ranking study considered 168 schemes which have an installed capacity of 63,328 MW and 149 of these were given A and B ranks, indicating high viability ( Manju Menon 2003). In addition to these over 900 mini and micro hydel projects have been identified to meet the local needs of the North East while the major portion of the power generated from the large dams will be evacuated to other parts of the country.

Though the projects are at different stages of development, some commonalities are observed in all cases. A clear observation is the social, economic, cultural and environmental impact of these dams on the affected people living in downstream areas.

While taking lower Subansiri project under consideration, it is found that the $116 \mathrm{~m}$. high dam would submerge 3,436 ha.of forests. The total requirement of forest land for the project is in Arunachal Pradesh and $856.3 \mathrm{ha}$. The submergence area of the lower Subansiri dam will extend over $70 \mathrm{~km}$. upstream along some of its tributaries such as the Kamala and the Sil. Since the submergence area is a gorge with steep slopes and rugged topography, relatively few villages will be directly displaced. According to the project authorities the dam will submerge the agricultural lands of two villages, Gengi and Siberite. The families to be affected belong to the Gallong tribe, a subgroup of the Adis. These are agricultural communities practicing jhum cultivation, terrace rice cultivation and wet rice cultivation near the river bed. Besides they also depend on forest for their livelihood. So, all these resources will no longer be available once they are displaced. According to the EIA report prepared by WAPCOS, New Delhi, for NHPC, the project affected people (PAP) will be offered housing and homestead land, cultivable land (one hectare), civic amenities, schools and vocational training in animal husbandry, horticulture, weaving and other activities. It has been seen that the Resettlement and Rehabilitation plan spelt out for the PAFs 38 hactares of cultivable land (one hectare for each family) and $200 \mathrm{sq} . \mathrm{km}$. of homestead land for each family will be given as compensation for a total 960.11 hactares of land.

Like Subansiri, Tipaimukh hydroelectric project also has been the bone of contention between the government and the affected people. The project is anticipated to submerge $275.50 \mathrm{sq}$. $\mathrm{km}$ of land surface in the state and to affect 191 sq.km. The dam is also anticipated to doom all the potentialities of the Barak catchment area. The project will submerge the national highway no. 53, the only alternative to Imphal Dimapur lifeline (NH No.39). Hence new alignment of the submergible points on the road will add a distance of another $60 \mathrm{kms}$ to the existing Imphal-Jiribam-Silchar road. Though Manipur and Mizoram have been promised 12 percent of the output as royalty, the critics have long been warning that the dangers far outnumber the potential benefits. For instance, the Naga leaders claimed that the dam would submerge the socially and economically important places. The site chosen for the dam on the Tuivai river was also prone to intense seismic activity. The dam will also submerge various historical and legendary sites and sacred groves with vital spiritual and cultural significance to the communities and lead to destruction of rich biodiversity which is threatening the peoples' right to life and livelihood. Like other development projects in the north east, here too, the people that are most adversely affected are tribes: the Zeliangrong a constituent of three Naga tribes and the Hmar will be the direct victims of the project.

According to the project plan, a 23 kilometers long and 26 meters high dam will be constructed along with a reservoir to retain 446 million cubic meters of water. The main canal would be $66.2 \mathrm{kms}$ long and a branch canal of 39.5 kilometers making it 105.7 kilometers in total.

Altogether, 38 villages would be submerged under the proposed project. In January 2003, the government issued notification for the acquisition of land from the villagers. Mention may be made that all the villages expected to be submerged fall under the proposed Bodoland Territorial Council (BTC) area. While the Brahmaputra Board, the implementing agency of the dam project claimed that only 20 percent of the potential displacees belonged to the Scheduled Tribes, according to the affected people the figure is around 90 percent. According to its estimation the Board has drawn up a Resettlement and Rehabilitation (R\&R) package at the cost of Rs .47 .89 crores, aiming to rehabilitate 18,473 people and 3, 271 families. However, in the opinion of the affected people, the government figure was extremely low and the actual figure comes to around 50,000 people belonging to 5,000 families. Moreover the figure did not include the number of potential displacees of the five villages newly added to the original 33 affected villages pointed out by the dam resistance committee that had launched a long struggle against the construction of the dam and the Brahmaputra Board. 
While the government claimed that it would compensate all the affected people of the dam project, by providing handsome $\mathrm{R}$ and $\mathrm{R}$ package, the people were not convinced. The villagers had their own view of the fate of the dam displaces based on their assessment of the affected people of similar projects as has been mentioned in an article published in the souvenir of the PDPKASS. The people of the projects who have not been given rehabilitation and some of the projects which have not been completed are mentioned in the article as affected people of Borlia river, Suklai, Champanadi, military base at Satgaon in Guwahati, Jagiroad paper mill, capital complex at Dispur, NEEPCO Duliajan Project at Kathalguri, Dinjan Military Base and Numaligarh Refinery project. The people were also aware of the fate of other projects, such as, Bhakranangal projects learnt from the interaction they had with the dam activists. Hence people felt that both the state government and Union Ministry of Water Resources have simply been fooling the people of Nalbari who were going to be affected by the project. Besides more than 40, 000 people were expected to be affected by the project, the government proposed to acquire another 34,000 acres of land, which is very fertile. Though the project was going to affect different communities such as Rabha, Rajbanshi, Nepalese, Bengalis, Santhals etc, the Bodos were demographically the largest groups to be affected in the area, most of whom were peasants. Hence acquisition of land from them was thus the acquisition of livelihood of these victims. In addition to this, the proposed project would submerge four high schools and forty primary schools, several primary health centres, temples, Namghars and other places of worship.

While the rehabilitation of the social and cultural assets of these victims would be practically impossible to achieve, the economic rehahabilitation was yet another hidden difficulty observed by the villagers. Though the Brahmaputra Board has prepared a separate R and R package for the displacees, only 47.89 crores had been allocated for the same. Moreover the potential displacees have lost faith in the state government and the claim of the Brahmaputra Board. Moreover the land selected by the government of Assam for the rehabilitation of the displacees were already occupied by thousands of refugees from East Pakisthan (present Bangladesh), the Nalbari district does not have sufficient land at its disposal to accommodate the displaced population.

While the Subansiri, Tipaimukh and Pagladia entails the story of land acquisition, and anticipated extent of displacement, the story of Gomti clearly demonstrates the experience of injustices to a large section of people. A $30 \mathrm{~km}$. high gravity dam was constructed across the Gumti river about $3.5 \mathrm{~km}$. upstream of Tirthamukh in South Tripura district for generating 8.60 MW of power from an installed capacity of $10 \mathrm{MW}$. The dam submerged a valley area of $46.34 \mathrm{sq}$. $\mathrm{km}$. This was one of the most fertile valleys in an otherwise hilly state, where arable flat land suitable for wet rice agriculture make up a mere 28 percent of the total land area. According to official records, 2, 558 tribal families were displaced from the Gumti project area. But this number only includes families who could produce land deeds to their land as proof of ownership of the submerged land leaving out a large number of families who could not do so.

According to Subir Bhowmick, the official estimates vary between 8, 000 to 10, 000 families or about 60, 000-70, 000 tribal people displaced by the project. According to official records, 2, 558 tribal families were displaced from the Gumti project area. But this number only includes families who could produce land deeds to their land as proof of ownership of the submerged land leaving out a large number of families who could not do so.

Though it is very much established in the literature mainly with the contribution of eminent environmentalists as Guha that the environmentalism of the third world is the environmentalism of the poor or as Dwivedi says, a livelihood approach is very much required to understand the environmentalism of south, the environmental justice approach also holds true to understand the situation of North East India. The ethnic minorities which are residing in the outskirts of the geography occupied by the dominant race or ethnic group, very often are the sufferers of such projects. In India and so also in South Asia, similar experience is observed. It has been seen that the poor are getting less importance when the question of harnessing of natural resources is concerned. In most cases it has been seen that impact of the developmental projects are more on the people who are living in the peripheral areas, not only geographically but also politically and socially most of whom are poor, with their own ethos of nature and culture, but very often are neglected by the growth oriented developmental paradigm of the state. Of course the livelihood of the poor is at stake in the region, as in the country and the rest of the third world countries, the ethnic communities and the communities of rural areas suffer seriously as is experienced by the people of color in the United States. The tribal people in North East have been seen to be the main victims of these developmental projects. The picture is quite similar in case of the rest of the country. It has been seen that out of the total displaces of the country tribal people records more than 50 percent the total displaces. Irony is that these tribal people comprise only 8 percent of the total population. The magnitude of sufferings that the tribal /indigenous people have gone through displacement is reflected in what Mullick et al say

"Every biosphere reserve in the country is on Adivasi land. Every major dams since the 1970s has been submerging adivasi land .Every wild life sanctuary in India is on adivasi homelands. Every national park is 
totally adivasi. Adivasi lands produce most of Indis's coal, bauxite, and mica. Almost $50 \%$ of the mineral wealth of India comes from adivasi areas. Yet, 85 per cent of the adivasis are below the poverty line. They form 50 per cent of those forcibly evicted from their homeland s by 'National Development Projects'. Forming about 8 percent of Indias people, the adivasis predominate in about 20 per cent of the most inhospitable, inaccessible yet perhaps the riches tracts of land. Yet, only one percent has any legal recognition of their land rights.'

While talking about Asia's situation Kullard and Parsoon says, there is also proliferation of national parks now covering about 4.5 per cent of Asia's area which has deprived local farmers of important grazing land and arable land. Conflicts over use versus nonuse of natural resources are often a result of initiatives from NGOs based in western Europe or North America .International organizations, motivated by the values found predominantly among a western urban middle class concerned about degradation caused by their own lifestyle, may thus pose a threat to local people and cultures as the latter's access to life sustaining resources are being curtailed.

In North East India, the picture though is yet to be clear, but it can rather be projected that about 80 percent of the total displaces would be tribal for the region predominantly inhabitated by the tribal people.

More over the apathy of the Indian Government towards the rehabilitation and resettlement glooms the picture. According to an estimate out of total 2130000 displacees by various types of projects between 1951 1990 around 53, 80,000 have not been rehabilated. Moreover the land acquisition Act of 1894 limits compensation to patta holders. This is a serious issue which comes on the way of proper resettlement and rehabilitation of the tribes. The tribal institution of land ownership does not give land right to a single person, the land is traditionally distributed among the members of the clan by the head and it does not have any government record As a result it comes on the way of proper compensation. This is observed in case of Gumti dam, where a majority of the affected people were deprived of rehabilitation. The same thing is also observed in case of Pagladia dam and is anticipated in case of other dams as Subansiri, Tipaimukh, etc.

The magnitude of injustices can be seen not only in terms of displacement but also increasing poverty. According to Fernandes and Bharali in Assam landlessness grew from 15.56 percent to 24.38 percent, the average area cultivated declined from 3.04 acres to 1.45 acres and the proportion of cultivators from 72.58 percent to 40.24 percent. Similar data can be given from other States. Common to them is the fact that after the project small and marginal farmers became landless and medium farmers joined the ranks of small and marginal farmers. Also support mechanisms such as ponds, wells, poultry, cattle and draft animals that supplement their income declined .

\section{Conclusion}

North East India exhibits social exclusion on different grounds due to its peculiar demographic and physiographic character. The region already has a perepharal syndrome in so far as its experience of development and inclusion in national economy is concerned. Moreover it also shows a double peripheralisation in so far as its ethnic communities of the region are concerned. This can be observed in relentless emphasis on growth oriented development projects in the land of North East India, with its emphasis on dam construction to keep the power demand of India shining unaffected. The tribal people of the region are under continuous threat to displacement due to the ever-increasing emphasis on energy generation. In one side there are communities who are in constant threat of health risk due to proposed uranium mining project in Meghalaya, other side there is stress on hydropower generation which altogether experience a new sense social exclusion to the otherwise nature based communities of the region. The apathy of the state and central government to look into the matter of these affected people is reflected in their continuing with the project without following the proper procedure of initiating such projects which has been pointed out by the activists of the region. In fact there remains a huge gap between the covert and overt intention of the state in so far as their right to environment and livelihood is concerned. This along with other apprehension of deprivation from culture and community life of the people thus makes us to understand social exclusion by emphasizing on ethnicity and the injustices they experience from lack of choice of right to safe and desired environment thereafter helping us understanding social exclusion not only from the perspective of environmentalism of poor, but also from environmental justice approach .

Reference

[1]. Wenz, Peter, The Importance of Environmental Justice, Merchant Carolyn Ecology Rawat Publications, Jaipur and New Delhi, 1996

[2]. Collin et al 1995, Environmental Racism: A Challenge to Community Development Journal of Black Studies, vol. 25, No 3, January

[3]. Bullard, Robert, Environmental Racism and the Environmental Justice Movement Bullard (ed), Confronting Environmental Racism, Boston South Press1993

[4]. Laduke, Winova, From Resistance to Regeneration' in Merchant Carolyn Ecology Rawat Publications Jaipur and New Delhi, 1996 
[5]. Sherry Cable and Michael Benson, Acting Locally: Environmental Injustice and Emergence of Grass-Roots Environmental Organizations, Social problems, Vol.40,No.4 (Nov) 1993.

[6]. Silver, Reconceptualising Social Disadvantage: Three Paradigms of Social Exclusion, in Social Exclusion: Rhetoric, Reality, Responses, Edited by Gerry Rodgers, Charles Gore, and Jose Figneiredo. Geneva: International Institute for Labour Studies 1995.

[7]. Williams Glyn and Mawdsley Emma, Postcolonial environmental justice: Government and governance in India, Geoforum, 37, 2006, 660-670 .

[8]. Amartya Sen Social Exclusion : Concept, Application and Scrutiny , Social Development papers No.1, Office of Environment and Social development, June 2000.

[9]. Walter Fernandes, Singur and the Displacement Scenerio, Economic and Political Weekly, 42 (n 3) January20-26, 2007, 203-206.

[10]. Tiplut Nongbri, Forest Policy in North East India Indian Anthropologists, 29:2 . 1999

[11]. A.C.Sinha , Beyond the Trees, Tigers and Tribes: Historical Sociology of the Eastern Himalayan Forests, Har -Anand Publications .New Delhi 1993.

[12]. Hussain, Monirul Interrogating Development: State, Displacement and Popular Resistance in North East India, Sage Publications India Pvt Limited 2008.

[13]. Manju Menon and et al, Large Dams in the North East: A Bright Future, The Ecologist Asia, Vol.11 No.1 January- March 2003

[14]. Bhowmik Subir , in The Ecologist Asia Vol 11, no.1, January-March 2003

[15]. Guha, Environmentalism: A Global History, Oxford University Press, New York,2000.

[16]. Ranjit Dwivedi, Environmental Movements in the Global South International Sociology March 2001 Vol. 16 (1) Sage, Thousand Oaks, CA and New Delhi, 2001

[17]. S.Bosu Mullick, Edwin Jaydas, Anto Akkara and Anita Jaydas, The Adivasi and Land, Indigenous Identity, Delhi, Navdin Prakashan Kendra 1993

[18]. Arne Kalland, Arne and Gerard Persoon Gerard (Eds), 1998, Environmental Movements in Asia Curzon Press1998.

[19]. Walter Fernandes and Gita Bharali, , Development Induced Displacement and Deprivation in Assam 1947-2000 : A quantitative and Qualitative Study of its Extent and Nature. Guwahati, Northeastern Social Research Centre , 2006. 